\title{
ERRATUM
}

\section{The Proton Momentum Distribution in Water and Ice}

G. Reiter, J.C. Li, J. Mayers, T. Abdul-Redah, and P. Platzman

Braz. J. Phys. 34, 142 (2004)

The authorship of the paper "The Proton Momentum Distribution in Water and Ice", Braz. J. Phys. 34, 142 (2004) was listed as G. Reiter, J.C. Li, J. Mayers, P. Platzman and F. Stillinger. It should be changed to G. Reiter, J.C. Li, J. Mayers, T. Abdul-Redah, and P. Platzman. The authors wish to thank F. Stillinger for many useful conversations. 